\title{
Multi Premises Network Based on Spectral Amplitude Coding Optical CDMA Systems
}

\author{
T. Eltaif*, N. Nicholas*, M. A. Alsaraj*, B. A. Hamida** \\ *Faculty of Engineering \& technology, Multimedia University, 75450 Bukit Beruang, Melaka, Malaysia \\ **Optoelectronics Laboratory, Faculty of Engineering, International Islamic University Malaysia (IIUM), 53100 Gombak, Kuala \\ Lumpur, Malaysia \\ tefosat@ieee.org, ntarenick@yahoo.com, alsarraj2012@yahoo.com, bg75760@yahoo.com
}

\begin{abstract}
The aim of this article is to introduce multi downstream passive optical network based on optical code division multiple access (OCDMA) technique, which is considered as a next-generation optical access network. Hence, incorporating this technique with passive optical network (PON) will enable the system to support higher bandwidth compared to the standard PON. The decoder is configured based on spectral coding because of its good noise suppression properties. Since the most important aspect of PON architecture is its simplicity, a multi PON access network, each PON comprises 9 users encoded by modified quadratic congruence (MQC) codes at the $\mathrm{C}$ band for downstream signals with channel spacing $25 / 50 \mathrm{GHz}$ is simulated. In this article low error rate transmission at high data rate for distances up to $28 \mathrm{~km}$ is demonstrated. Variation in the results was studied when varied fiber length, data rate and different effective power were applied. It has been shown that OCDMA is capable of providing gigabit-per-second for each user. The receiver sensitivity is affected by the multi premises system, where the best system performance can only be achieved when the effective power is $-1 \mathrm{dBm}$. Nevertheless, the results have indicated that the proposed PON based on spectral amplitude coding OCDMA technique is capable to support multi premises network.
\end{abstract}

Keywords - Modified quadratic congruence (MQC) codes, Optical code division multiple access (OCDMA) system, passive optical network (PON).

\section{INTRODUCTION}

There are some factors are considered as a drawback of the access networks, those factors are limited bandwidth, high costs, poor flexibility, and low security. Then, installing optical-fiber links is more important than ever before for practical use in access networks. Passive optical networks (PONs) and different multiplexing technologies have been proposed in this context, including wavelength-division multiplexing (WDM), time-division multiplexing (TDM), and optical-code-division multiplexing (OCDM) [1-3]. TDM and WDM technologies have been proposed for PON, this emerging technology becomes more favorable as the required bandwidth increases, but it has failed to attract attention from industry because of the high cost of the associated optical components. Recently, optical CDMA system has become more attracted because of its advantages over the other technologies, such as its asynchronous access capability, flexibility of user allocation, support of variable bit rates, burst traffic, and security against unauthorized users.

Passive optical network (PON) is a fiber-based access network that provides huge bandwidth in a cost effective manner. PON architecture consist of three parts, optical line terminal (OLT), located in the central office, and a number of optical network units (ONUs) located at the users' premises and the channel linked OLT to ONUs called optical distributed unit (ODU). A passive optical splitter/combiner broadcasts traffic from the OLT to the ONUs (downstream direction) and transmits traffic from the ONUs to the OLT (upstream direction). PONs appears in different approaches, depending on the multiple access schemes they deploy in both directions, such as TDMA, WDM and Optical Code Division Multiple Access (OCDMA) [1-3]. The point to multi point (P2MP PON) has advantages over the standard point to point (P2P) technology in terms of capital and operational expenditure. Where number of ONUs in a PON system is between 16 and 64, and such a network will reduce power consumption of the $\mathrm{CO}$ equipment [4].

OCDMA technique is a point-to-multipoint technology where each end-user matches its own communication from the transmitted signal. Correspondingly, PON architecture design is also considered as a point to- multipoint access technology with passive components, such as splitters, couplers, fiberoptics etc., where potentially the cost is reduced. OCDMA is a promising technique, offering random access to the entire bandwidth along with advantages such as increased security, and increased flexibility, where the capacity can be upgraded by adding a code-based dimension to the FTTH system as shown in table 1. Nobuyuki et al, have introduced bidirectional PON based on OCDMA technique and error free transmission of asynchronous, 4-user, 10Gbps OCDMA system was successfully reached [5]. One of OCDMA system drawbacks is the overlapping between the users and in 1993 Zaccarin and Kavehrad proposed detection scheme called spectrum amplitude coding (SAC) [6], this detection scheme has the ability to cancel the overlapping between the users and it offers lower cost which is suitable for passive optical network (PON) applications.

In this paper, we introduced multi downstream signals based on OCDMA technique, which is considered as the next- 
generation optical access network. The OCDMA link is apparent to the input channel's data procedure with security. It maintains burst secure traffic and random access protocols. Hence, incorporating this technique with PON will enable the system to support higher bandwidth compared to the standard PON [1-3].

\section{Multi Premises Configuration}

The architecture of OCDMA-PON transceiver is clarified in this paper, the architecture contains optical network unit (ONU) which is a device that terminates any one of the distributed endpoints of an optical distribution network, and optical line terminal (OLT) located at the head-end or central office. The decoder is configured based on spectral amplitude coding scheme because of it has the ability to eliminate the multiple access interference (MAI) [6].

A simulation of single OLT unit comprises 9 users encoded by modified quadratic congruence (MQC) codes [7] at the $\mathrm{C}$ band for downstream signals with channel spacing 25/50 GHz. code. More details of MQC can be found in [7]. In MQC code, the code length is $p^{2}+p$ and its weight is $p+1$. This allows a total number of users $N=p^{2}$. Therefore under the worst case i.e., $\tau_{n}=0$, for all $n$, synchronized condition [8]. The 9 signals encoded by MQC code, tabulated at table 1, are send to multi premises (i.e., ONU's) access network as shown in Fig.1. In this simulation, the multi-wavelength mode-locked laser (M-WMLL) is used as a broadband source in C-band, and it is modulated by a Mach-Zehnder modulator (MZM) with a $10 \mathrm{Gbps}$ non return-to-zero (NRZ) pseudo-random bit sequence (PRBS) data $\left(2^{31}-1\right)$ from a pulse generator. The optical impulse produced by M-WMLL source is split into $\mathrm{W}$ ( $\mathrm{w}$ is number of weights in the code) branches which are coupled at the end after it pass through optical filters. At the receiver side, the signal is decoded by the spectral amplitude coding detection scheme.

TABLE 1. MQC CODE Properties $(P=3)$

\begin{tabular}{|c|c|c|c|c|c|c|c|c|c|c|c|c|c|}
\hline & & \multicolumn{12}{|c|}{ CODE SPECTRAL CHIPS } \\
\hline & & $\begin{array}{l}\mathrm{C} \\
1\end{array}$ & $\begin{array}{l}\mathrm{C} \\
2\end{array}$ & $\begin{array}{l}\mathrm{C} \\
3\end{array}$ & $\begin{array}{l}\mathrm{C} \\
4\end{array}$ & $\begin{array}{l}\mathrm{C} \\
5\end{array}$ & $\begin{array}{l}\mathrm{C} \\
6\end{array}$ & $\begin{array}{l}\mathrm{C} \\
7\end{array}$ & $\begin{array}{l}\mathrm{C} \\
8\end{array}$ & $\begin{array}{l}\mathrm{C} \\
9\end{array}$ & $\begin{array}{c}\mathrm{C} \\
10\end{array}$ & $\begin{array}{c}\mathrm{C} \\
11\end{array}$ & $\begin{array}{c}\mathrm{C} \\
12\end{array}$ \\
\hline \multirow{9}{*}{ 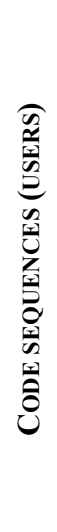 } & 1 & 1 & 0 & 0 & 0 & 1 & 0 & 0 & 1 & 0 & 0 & 0 & 1 \\
\hline & 2 & 0 & 1 & 0 & 0 & 0 & 1 & 0 & 0 & 1 & 0 & 0 & 1 \\
\hline & 3 & 0 & 0 & 1 & 1 & 0 & 0 & 1 & 0 & 0 & 0 & 0 & 1 \\
\hline & 4 & 0 & 1 & 0 & 0 & 1 & 0 & 1 & 0 & 0 & 1 & 0 & 0 \\
\hline & 5 & 0 & 0 & 1 & 0 & 0 & 1 & 0 & 1 & 0 & 1 & 0 & 0 \\
\hline & 6 & 1 & 0 & 0 & 1 & 0 & 0 & 0 & 0 & 1 & 1 & 0 & 0 \\
\hline & 7 & 0 & 1 & 0 & 1 & 0 & 0 & 0 & 1 & 0 & 0 & 1 & 0 \\
\hline & 8 & 0 & 0 & 1 & 0 & 1 & 0 & 0 & 0 & 1 & 0 & 1 & 0 \\
\hline & 9 & 1 & 0 & 0 & 0 & 0 & 1 & 1 & 0 & 0 & 0 & 1 & 0 \\
\hline
\end{tabular}
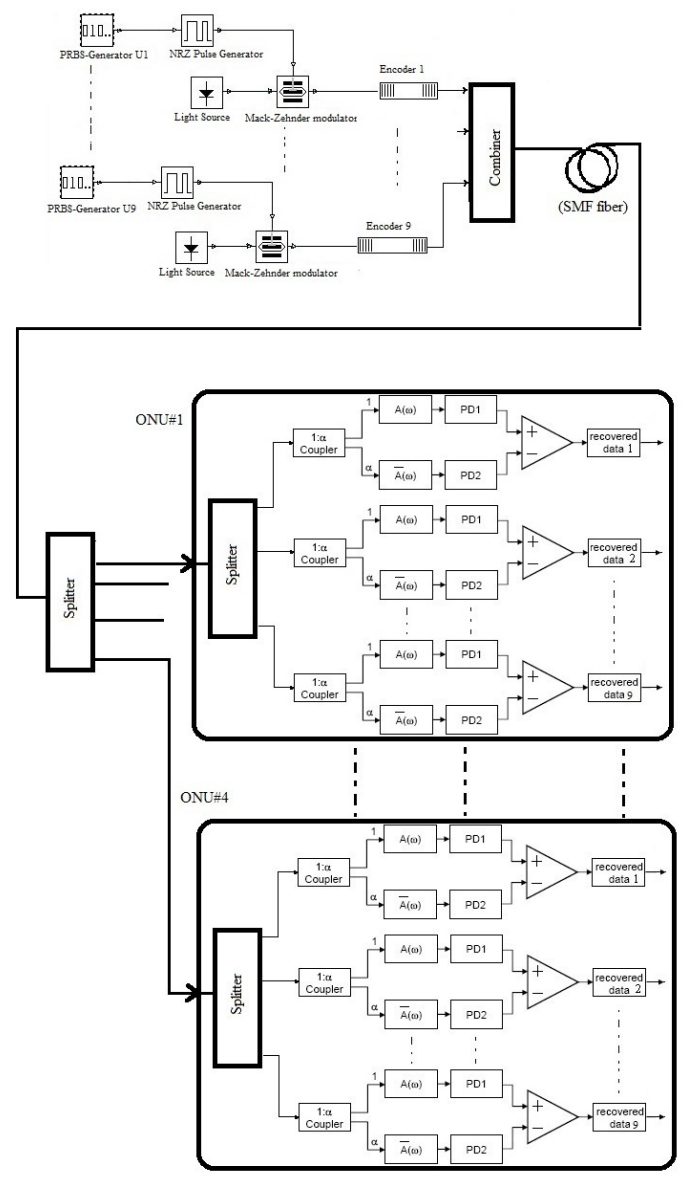

Figure 1. MONU block diagram

The multi premises (i.e., ONU units) increased as number of weights of MQC code increased. In this article low error rate transmission at high data rate for distances up to $40 \mathrm{~km}$ is achieved. Variation in the results was studied when fiber length and data rate were varied and different transmission power was applied. The network scalability of fiber link distances as well as bit rate and effective power, considered the fiber link loss and multiple-access interference (MAI). The results have indicated that the proposed PON based on SAC OCDMA can be capable to support local area network as an application for fiber to the home.

\section{RESULTS AND DISCUSSION}

Fig.2 shows the relationship between the number of simultaneous users and the bit error rate (BER), when the prime number used for MQC code construction is $p=3$, $0 \mathrm{dBm}$ transmit power and $10 \mathrm{Gbps}$ over various channel length. Clearly, from the figure most of the users have good performance, and the system can support 9 users for distance up to $40 \mathrm{Km}$. The system also can run at high data rate up to $12 \mathrm{Gbps}$ to reach BER of $10^{-9}$ as shown in Fig.3. 


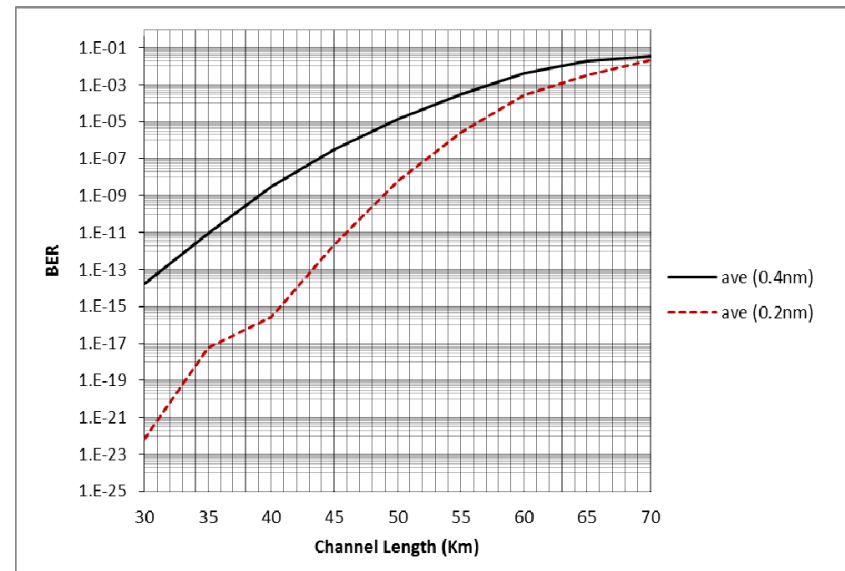

Figure 2. BER versus channel length

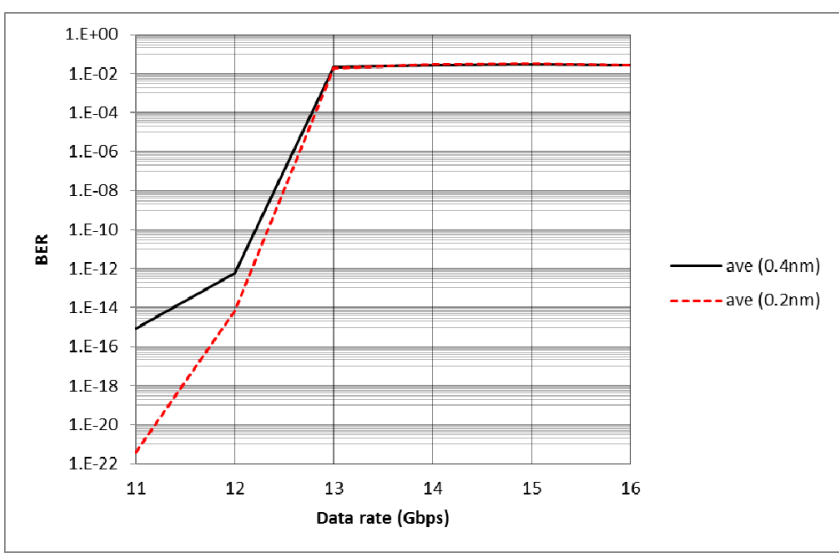

Figure 3. BER versus data rate

Fig.4-6 show the results of multi premises optical network unit, in this section, a single OLT compiling 9 users at channel spacing $50 \mathrm{GHz}$, each encoded by MQC code when the prime number is 3 . The transmit signals send over a single mode fiber to 4 ONU's, each has 9 decoders. Hence, the system can support up to 36 users. Therefore, multi premises are directly proportional with the number of weights of the MQC code. Clearly, because of multi premises, the maximum channel length the system can support is $28 \mathrm{Km}$ as shown in Fig. 4 .

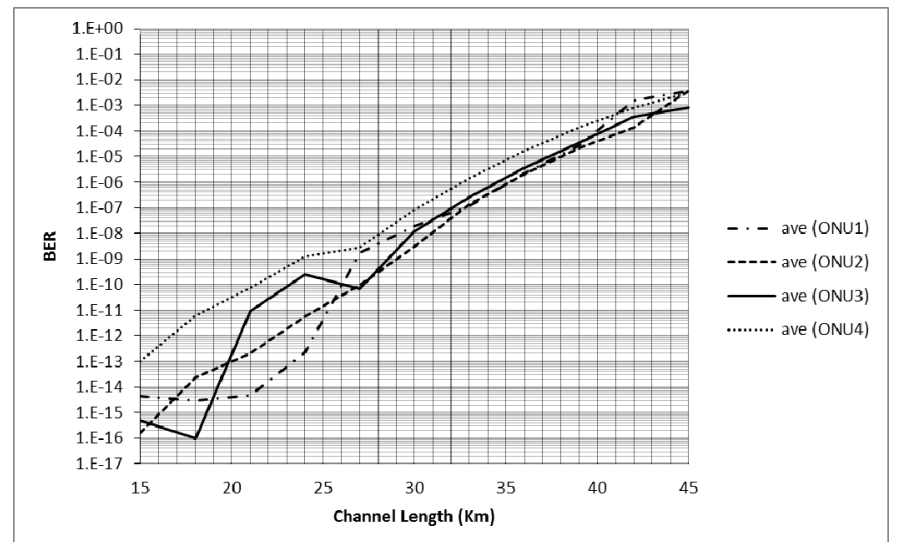

Figure 4. BER versus channel length
The BER versus the data rate at $15 \mathrm{Km}$ and $0 \mathrm{dBm}$ transmit power is shown in Fig.5 and clearly the system still have sufficient value of BER even at $12 \mathrm{Gbps}$. The receiver sensitivity is affected by the multi premises system, where the best system performance can only be achieved when the effective power is $-1 \mathrm{dBm}$ as shown in Fig.6. In addition the signal degrades because of combiners and splitter losses and the nonlinearity of the fiber due to high power loading at the input and signal optical amplification.

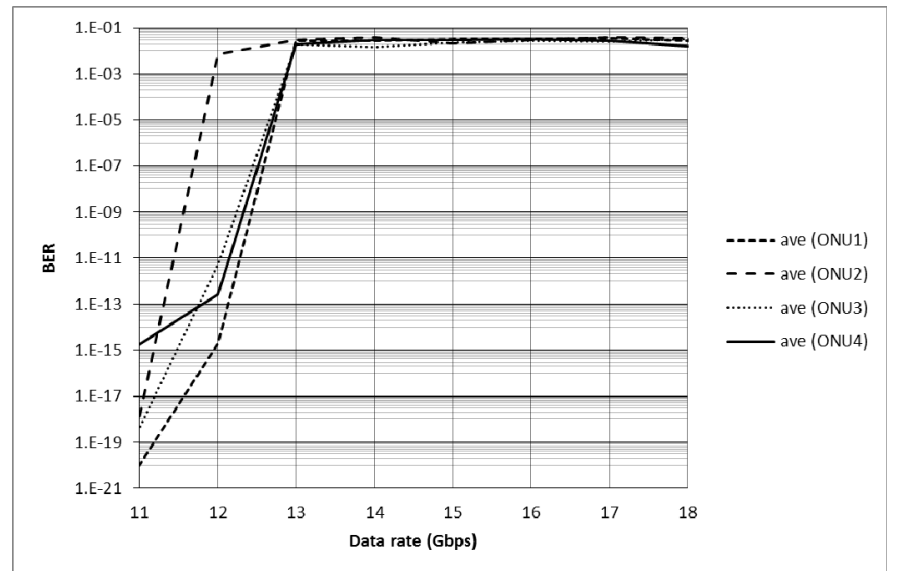

Figure 5. BER versus data rate

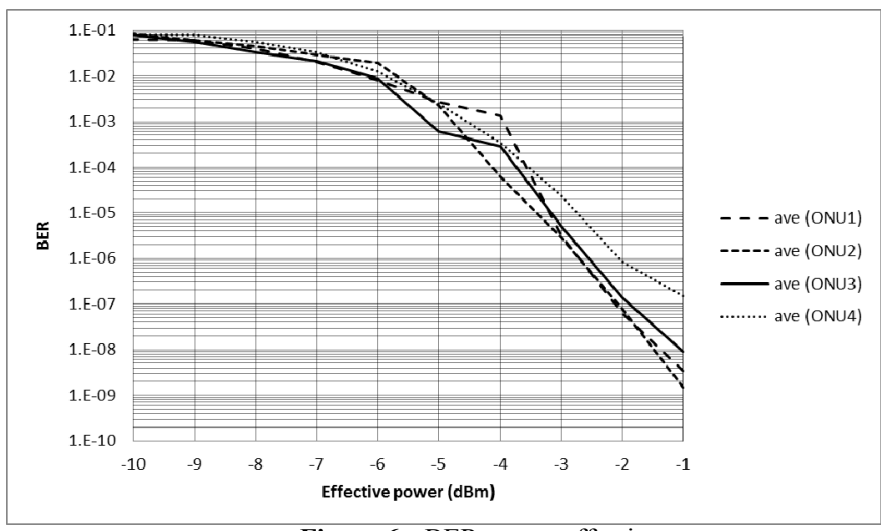

Figure 6. BER versus effective power

\section{CONCLUSIONS}

The primary aim of this paper was to introduce multi premises network based on coding technique. The system consists of a single OLT unit, which is capable of supporting up to 4 ONUs. The OLT combing 9 subscribers, each subscriber data encoded by MQC code and send over SMF fiber. Each ONU has 9 balanced detection schemes to detect the encoded data. The number of ONU's is directly proportional with the number of weights of the MQC code. Simulation results show that all the users can achieve sufficient BER even at high data rate. 


\section{ACKNOWLEDGMENT}

This work was supported by mini fund research program, Multimedia University under grand No. MMUI/130089.

\section{REFERENCES}

[1] G. H. Shiraz, and M. M. Karbassian, "Optical CDMA networks principles, analysis and applications", John Wiley \& Sons Ltd, $1^{\text {th }}$ edition, West Sussex, 2012.

[2] P. R. Prucnal, "Optical Code Division Multiple Accesses: Fundamentals and Applications", Taylor \& Francis, Boca Raton, 2005.

[3] Chongfu Zhang. "Passive optical network based on optical-codedivision," SPIE Newsroom 10.1117/2.1201006.002981, 2010.

[4] W. Zou, H. M. H. Shalaby, and H. G. Shiraz, Modified quadratic congruence codes for fiber Bragg-grating-based spectral-amplitude coding optical CDMA systems, J. Lightw. Tech. LT-19, pp. 1274-1281, 2001.

[5] N. Kataoka, N. Wada, G. Cincotti, K. Kitayama, "DispersionCompensation-Free, Long-Reach OCDMA-PON System with Passive Remote Node at Arbitrary Position using Single Multi-port Encoder/Decoder", Conference on Lasers and Electro-Optics (CLEO) and Quantum Electronics and Laser Science Conference (QELS), pp. 12. 2010 .

[6] D. Zaccarin and M. Kavehrad, "An optical CDMA system based on spectral encoding of LED," IEEE Photon. Technol. Lett., vol. 5, no. 4, pp. 479-482, Apr. 1993.

[7] T. Keiji, A. Akira, and H. Yukio, "IEEE 802.3av 10G-EPON Standardization and Its Research and Development Status," J. Lightw. Tech, vol. 28, No. 4, pp.651-661, 2010.

[8] J. A. Salehi, "Code division multiple-access techniques in optical fiber networks-Part I," IEEE Trans. Commun., 37, no. 8, 824-842, 1989.

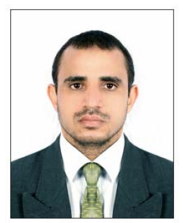

T. Eltaif (S'06-M'13) was born in Gharian, Libya, in 1979 He received his BSc degree in communication engineering from University of Tripoli, Tripoli, Libya, and MSc and $\mathrm{PhD}$ degrees in Micro-Engineering \& Nanoelectronics from National University of Malaysia, Bangi, Malaysia, in 2005 2009, respectively.

During his study he joined National University of Malaysia as a graduate research assistant (GRA) from August 2007 until December
2008. His job as a researcher carried the following responsibilities: research on Optical Code Division Multiple Access technique (OCDMA) systems. He joined Photronix Technologies (M) Sdn Bhd, Puchong, Malaysia (August 2008- October 2011) as a product and research engineer in fiber Bragg grating. His assignment was as a researcher on fiber Bragg grating (FBG) for sensor and communication application, preparation and selection of suitable fiber for fiber Bragg grating production and handling the technical issues regarding customer's inquiries and orders in cooperation with the FBG Unit Head. Currently he is a senior lecturer at Multimedia University (MMU), Melaka, Malaysia.

Dr. Eltaif is a member to IEEE Photonics Society, Society of Photo-Optical Instrumentation Engineers (SPIE), and he is a reviewer in severa international journals and his current research interests include optical CDMA, spread spectrum communications, fiber Bragg grating, and weigh in motion technology.

N. Nicholas photograph and biography not available at the time of publication.

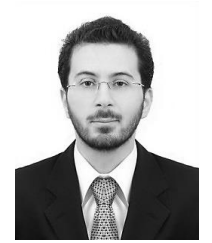

M. A. Alsaraj He is currently working toward the BEng (Hons) Electronics majoring in Telecommunications a Multimedia University (MMU), Melaka Campus, Malaysia. Expect to finish in Nov 2013.

In 2012, he joined Advanced Communications \& Electronics Systems Co Ltd., Jeddah, Saudi Arabia, where he was with RF Department as Full-time Trainee Engineer. He Participated in the In Building Solution (IBS) Projects Stages (Designing, Implementing and Testing). His current research interests include optical CDMA, spread spectrum communications.

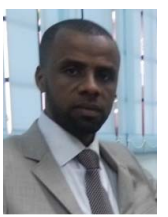

B. A. Hamida received the BSc degree in BSc Computer Engineering from Faculty of Engineering Tajoura, Libya, Sep 1996, the MSc degree in microelectronics from University Kebangsaan Malaysia UKM, Malaysia, in July 2007 and PhD degree in Electrical and Computer Engineering-International Islamic University Malaysia, in Feb 2013. Currently, he is a postdoctoral fellow at International Islamic University Malaysia, Malaysia. He is doing his research in the field of optical communication systems. His current research interests are Q-switched fiber lasers, passive optical networks PONs and optical code division multiple access OCDMA, and dual-wavelength thulium-doped fiber laser. 